\title{
The Effect of Histidine Oxidation on the Dissociation Patterns of Peptide Ions
}

\author{
Juma D. Bridgewater, R. Srikanth, Jihyeon Lim, and Richard W. Vachet \\ Department of Chemistry, University of Massachusetts Amherst, Massachusetts, USA
}

Oxidative modifications to amino acid side chains can change the dissociation pathways of peptide ions, although these variations are most commonly observed when cysteine and methionine residues are oxidized. In this work we describe the very noticeable effect that oxidation of histidine residues can have on the dissociation patterns of peptide ions containing this residue. A common product ion spectral feature of doubly charged tryptic peptides is enhanced cleavage at the C-terminal side of histidine residues. This preferential cleavage arises as a result of the unique acid/base character of the imidazole side chain that initiates cleavage of a proximal peptide bond for ions in which the number of protons does not exceed the number of basic residues. We demonstrate here that this enhanced cleavage is eliminated when histidine is oxidized to 2-oxo-histidine because the proton affinity and nucleophilicity of the imidazole side chain are lowered. Furthermore, we find that oxidation of histidine to 2-oxo-histidine can cause the misassignment of oxidized residues when more than one oxidized isomer is simultaneously subjected to tandem mass spectrometry (MS/MS). These spectral misinterpretations can usually be avoided by using multiple stages of MS/MS (MS ${ }^{\mathrm{n}}$ ) or by specially optimized liquid chromatographic separation conditions. When these approaches are not accessible or do not work, N-terminal derivatization with sulfobenzoic acid avoids the problem of mistakenly assigning oxidized residues. (J Am Soc Mass Spectrom 2007, 18, 553-562) (C) 2007 American Society for Mass Spectrometry

$\mathrm{M}$ ass spectrometry (MS) is a powerful method for identifying amino acid modifications to peptides and proteins. Such identifications are important in studies of protein post-translational modifications and in techniques that use covalent labeling to study protein structure. An emerging set of methods in the latter category are techniques that rely on oxidative modifications as indicators of protein structure. These methods use radicals (such as $\cdot \mathrm{OH}$ ) to modify solventexposed [1-10] or metal-bound amino acids [11-18]. Tandem MS (MS/MS), typically in conjunction with proteolytic digestion, is then used to identify oxidatively modified residues and information about protein structure is then derived. A modified amino acid is determined by finding product ions whose $\mathrm{m} / \mathrm{z}$ ratios are shifted from expected values.

Although oxidative modifications often do not change peptide ion dissociation patterns, there are several examples in which they do. Oxidative modifications to cysteine and methionine residues have very noticeable effects on peptide ion dissociation patterns. For example, oxidation of cysteine to cysteic acid in

Published online December 8, 2006

Address reprint requests to Dr. Richard W. Vachet, Department of Chemistry, Lederle GRT 701, 710 N. Pleasant St., University of Massachusetts, Amherst, MA 01003, USA. E-mail: rwvachet@chem.umass.edu

Present address: Department of Developmental \& Molecular Biology, Albert Einstein College of Medicine, Jack and Pearl Resnick Campus, 1300 Morris Park Avenue, Ullmann Building, Room 405, Bronx, NY 10461. some cases can lead to very selective peptide dissociation and in other cases to more efficient overall peptide dissociation [19-22]. The strong acid character of cysteic acid enhances peptide bond dissociation at its C-terminal side and can allow mobilization of an additional proton that initiates cleavages more efficiently at other peptide bonds as well. Oxidation of cysteine to cysteine sulfinic acid also leads to selective dissociation on the C-terminal side of this residue when the peptide charge state does not exceed the number of arginine residues in the peptide $[23,24]$. Methionine oxidation to methionine sulfoxide can also have a dramatic effect on peptide ion dissociation patterns [25-29]. When the number of protons on the peptide does not exceed the number of basic residues, product ion spectra of peptides containing methionine sulfoxide are dominated by a neutral loss of methane sulfenic acid $\left(\mathrm{CH}_{3} \mathrm{SOH}\right)$ [29]. Indeed, in many cases no other sequence information is present, highlighting the effect that this oxidative modification can have.

Whereas cysteine and methionine residues are readily oxidized, other amino acids such as those with aromatic side chains are also susceptible to oxidation [30], and oxidation of some of these residues might affect peptide ion dissociation patterns. During our work with oxidized peptides, we have observed that oxidation of histidine to 2-oxo-histidine can change peptide dissociation patterns in very noticeable ways. Understanding the effect of this oxidative modification 
to histidine on dissociation patterns is important for correctly interpreting tandem mass spectra of peptide ions containing this residue. In general, histidine oxidation is not only important for methods that rely on oxidative modifications as indicators of protein structure, but more broadly speaking oxidative modifications to this residue are commonly found in proteins from cells that have undergone oxidative stress [31-33]. Indeed, oxidation of histidine to 2-oxo-histidine in proteins has been suggested as a good marker of cellular oxidative stress [34]. Thus, any studies that use MS to understand protein modifications associated with oxidative stress are likely to analyze peptides and proteins with 2-oxo-histidine. In this work we describe the effect that this oxidative modification to histidine can have on the dissociation patterns of peptide ions, attempt to understand its cause, and suggest a means of avoiding spectral misinterpretations that are possible when this modification is present in peptides.

\section{Experimental}

Materials

Hydrogen peroxide (30\%), formic acid, tris(hydroxymethyl)-aminomethane (Tris), and tris(hydroxymethyl) aminomethane hydrochloride (Tris- $\mathrm{HCl}$ ) were obtained from EM Science (Gladstone, NJ). Dithiothreitol (DTT), sodium ascorbate, ascorbic acid, copper (II) sulfate, 3-morpholinopropanesulfonic acid (MOPS), ammonium acetate, triethylamine, and tetrahydrofuran (THF) were purchased from Sigma-Aldrich (St. Louis, MO). Acetic acid and HPLC-grade methanol were obtained from Fisher Scientific (Fair Lawn, NJ). Chymotrypsin was obtained from Roche Diagnostics (Indianapolis, IN) and trypsin was obtained from Promega (Madison, WI). Distilled, deionized water was generated with a Millipore (Burlington, MA) Simplicity 185 water purification system.

The peptides angiotensin I (DRVYIHPFHL) and angiotensin II (DRVYIHPF) were obtained from Sigma. The prion peptide Ac-PHGGGWGQ- $\mathrm{NH}_{2}$ was a gift from Prof. Colin Burns of East Carolina University. The peptides VSGFHPSDIEVDLL and VNHVTLSQPK are proteolytic fragments of the protein $\beta$-2-microglobulin $(\beta 2 \mathrm{~m})$, which was obtained from Research Diagnostics (Flanders, NJ). To digest $\beta$-2-microglobulin $(\beta 2 \mathrm{~m})$, a 200 $\mu \mathrm{L}$ solution of the protein $(10 \mu \mathrm{M})$ buffered at $\mathrm{pH} 7.4$ with MOPS was mixed with $100 \mu \mathrm{M}$ DTT, $5 \mu \mathrm{g}$ of chymotrypsin, $5 \mu \mathrm{g}$ of trypsin, and incubated overnight at $37^{\circ} \mathrm{C}$. The reaction was terminated by changing the $\mathrm{pH}$ of the solution to about 2 by the addition of acetic acid. The peptide NVMGHNW is a proteolytic fragment of azurin from Pseudomonas aeruginosa, which was obtained from Sigma. A $500 \mu \mathrm{L}$ solution of azurin (30 $\mu \mathrm{M})$ at $\mathrm{pH} 7.4$ was digested overnight with $5 \mu \mathrm{g}$ of trypsin, $5 \mu \mathrm{g}$ of chymotrypsin, and $10 \mathrm{mM}$ DTT at $37^{\circ} \mathrm{C}$. The reaction was terminated by lowering the $\mathrm{pH}$ to about 2 with acetic acid. The peptide HYGKHHQTY is a proteolytic fragment of Fe-superoxide dismutase (FeSOD), obtained from Sigma. Fe-SOD $(30 \mu \mathrm{M})$ was digested in the same manner as azurin, but no DTT was added.

\section{Peptide Oxidation}

All the peptides and proteins were oxidized using metal-catalyzed oxidation (MCO) reactions as described previously $[14,15,18] . \beta 2 \mathrm{~m}$, azurin, and Fe-SOD were oxidized at protein concentrations of $20-60 \mu \mathrm{M}$ in solutions that were buffered with Tris/Tris- $\mathrm{HCl}$ or MOPS at $25-100 \mathrm{mM}$ in open microcentrifuge tubes. Total sample volumes were $<200 \mu \mathrm{L}$. For $\beta 2 \mathrm{~m}$, an equimolar concentration of copper (II) sulfate was added, whereas azurin and Fe-SOD natively bind $\mathrm{Cu}$ and $\mathrm{Fe}$, respectively, so no metal was added. As we described previously $[14,15,18]$, each of these proteins is selectively oxidized at the amino acids that bind these metals. Detailed MCO reaction conditions for $\beta 2 \mathrm{~m}$ [15], azurin [14], and Fe-SOD [18] can be found in our previous work. Angiotensin I, angiotensin II, and the prion peptide were oxidized at concentrations between 100 and $500 \mu \mathrm{M}$. After adding an equimolar amount of copper (II) sulfate, the MCO reactions were initiated by the addition of ascorbate $(10 \mathrm{mM})$, whereas atmospheric $\mathrm{O}_{2}$ acted as the oxidant. Reactions were stopped by the addition of $1 \%$ (by volume) of glacial acetic acid.

\section{Peptide Derivatization}

N-terminal derivatization of the peptides was performed using 2-sulfobenzoic acid anhydride. This anhydride was prepared at a concentration of $0.1 \mathrm{M}$ in dry THF just before use. The peptide solution was diluted with triethylamine to a final concentration of $50 \mathrm{mM}$ and an equal volume of the 2-sulfobenzoic acid anhydride solution was added so its final concentration was $50 \mathrm{mM}$. The mixture was vortexed for $2 \mathrm{~min}$ and excess solvent was evaporated under a stream of $\mathrm{N}_{2}$ gas to dryness. The sample was redissolved in water and the peptide was purified using $C_{18}$ zip-tips.

\section{Instrumentation}

All mass spectral analyses were performed on a Bruker (Billerica, MA) Esquire LC quadrupole ion trap mass spectrometer. Typically, the needle voltage was kept at 3-4 kV; the capillary temperature was set to $250{ }^{\circ} \mathrm{C}$; $10-60 \mathrm{~V}$ was applied to skimmer 1 ; and the capillary offset voltage was set between 20 and $60 \mathrm{~V}$. For direct injection experiments the sample was delivered at 1 $\mu \mathrm{L} / \mathrm{min}$ using a syringe pump. HPLC-MS analyses of the peptides were conducted using an HP1100 (Agilent, Wilmington DE) system with a Zorbax $\mathrm{C}_{18}$ column (4.6 $\times 150 \mathrm{~mm}$; Agilent). The LC effluent was split in a 1:4 ratio with the smaller outlet being fed into the electrospray ionization (ESI) source of the quadrupole ion trap mass spectrometer. For separation of the oxidized an- 
giotensin isomers, an atypical binary gradient was used. The two mobile phases that were used were (A) water with $0.1 \%$ formic acid and (B) a $57 / 38 / 5$ mixture of methanol/water/acetonitrile with $0.1 \%$ formic acid. During the separation of the oxidized angiotensin I isomers, the following percentage increases of mobile phase B were made: $0-4 \mathrm{~min}, 10-50 \% ; 4-10 \mathrm{~min}$, $50-70 \%$; 10-30 $\mathrm{min}, 70-90 \%$; 30-31 $\mathrm{min}, 90-100 \%$. For separation of the oxidized prion peptide isomers, the same mobile phases were used, but the percentage increases of mobile phase B were: $0-4 \mathrm{~min}$, hold at $10 \%$; 4-6 $\mathrm{min}, 10-30 \% ; 6-26 \mathrm{~min}$, hold at 30\%; $26-28 \mathrm{~min}$, $30-100 \%$.

\section{Results and Discussion}

\section{Oxidation Eliminates Preferential Cleavages at Histidine Residues}

Peptide ions containing fewer protons than basic residues often dissociate preferentially at the C-terminal side of histidine. This effect is especially notable in the product ion spectra of doubly protonated peptides containing a single arginine residue $[35,36]$. Both experimental and theoretical studies have shown that this enhanced dissociation is initiated by proton transfer from the side chain of histidine to an adjacent carbonyl and the subsequent formation of a stable bicyclic structure [37-40]. Because of its relatively high proton affinity, histidine is protonated typically in tryptic peptide ions, but having a lower proton affinity than arginine, it can readily transfer its proton. An enhanced dissociation pathway is observed when the nucleophilic imino nitrogen of histidine's side chain attacks the electrophilic carbonyl produced after proton transfer (Scheme 1). The b-type product ion that is formed does not have the typical oxazolone structure but rather has the aforementioned bicyclic structure involving the imidazole ring of histidine.

When the side chain of histidine is modified by the net addition of one oxygen atom $(+16 \mathrm{Da})$, the preferential cleavage at the C-terminal side of histidine is no longer prominent. Figure 1 shows the tandem mass spectrum of doubly protonated angiotensin I (DRVYIHPFHL). The product ion spectrum of the unoxidized ion (Figure 1a) has several predominant ions, including $\mathrm{y}_{2}, \mathrm{y}_{4}, \mathrm{~b}_{6}, \mathrm{~b}_{8}, \mathrm{~b}_{9}{ }^{2+}$, and $\mathrm{y}_{9}{ }^{2+}$. The $\mathrm{y}_{4}, \mathrm{~b}_{6}$, and $b_{9}{ }^{2+}$ ions arise from peptide bond cleavage on the C-terminal side of His6 or His9. When angiotensin I is oxidized at His9, the resulting product ion spectrum of the doubly protonated parent ion is notably different (Figure 1b). One prominent difference is the reduction in the abundance of the $b_{9}{ }^{2+}$ ion in Figure $1 b$. Oxidation of His9 eliminates the enhanced cleavage at the Cterminal side of this residue. Presumably, the mechanism shown in Scheme $\mathbf{1}$ occurs less readily when histidine is oxidized. Interestingly, the enhanced cleavage at the C-terminal side of His6 is still observed because this residue is unmodified and, in fact, the

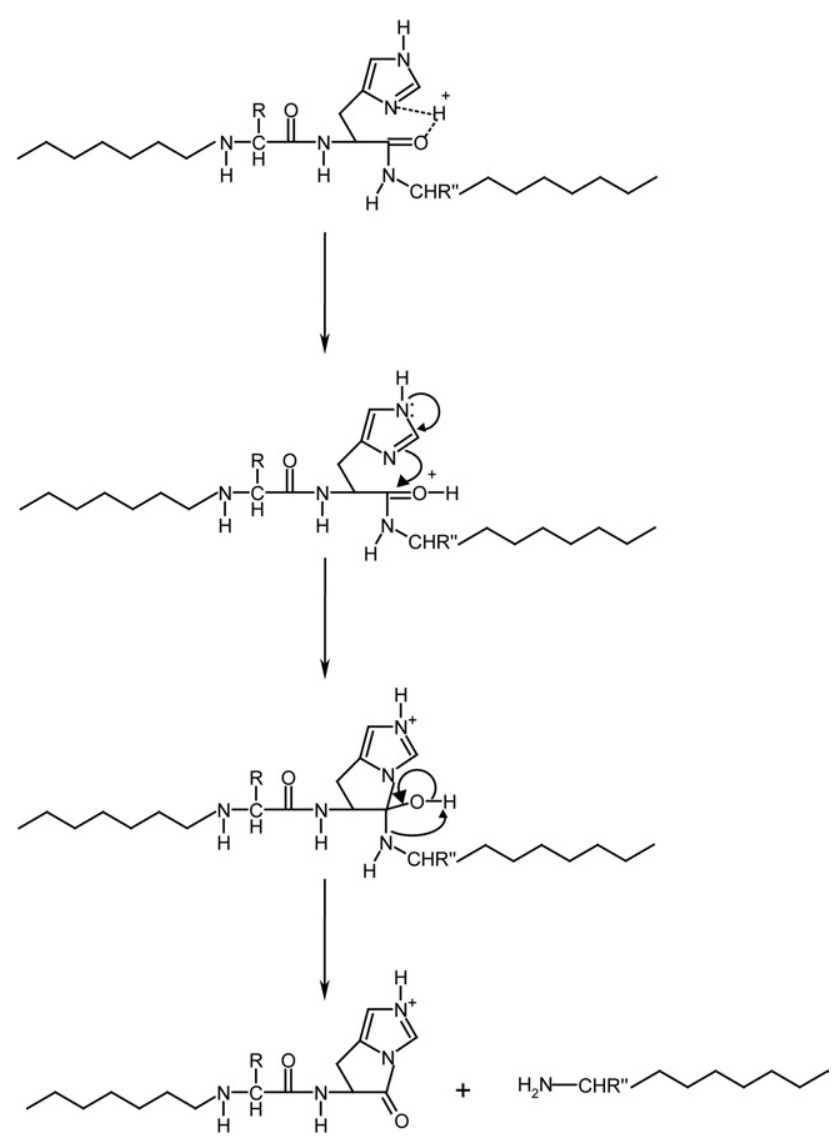

Scheme 1. Proposed mechanism [40] for the preferential formation of $b$ ions on the $\mathrm{C}$-terminal side of histidine residues

$\mathrm{b}_{6} / \mathrm{y}_{4}$ pair is now clearly the dominant dissociation pathway. Two other results are noteworthy about the product ion spectrum in Figure 1b. First, the relative abundance of the $\mathrm{y}_{9}{ }^{2+}$ product ion is reduced and, second, the relative abundances of the $b_{8}$ and $y_{2}$ product ions are significantly reduced. The reason for the decreased abundance of the $\mathrm{y}_{9}{ }^{2+}$ product ion is unclear. The reduced abundances of the $b_{8}$ and $y_{2}$ product ions, however, are probably attributable to oxidized His9 no longer being protonated in the low-energy structures of the $(\mathrm{M}+2 \mathrm{H})^{2+}$ ion of angiotensin I, which makes proton transfer to the adjacent peptide bond and formation of the $b_{8}$ ion less likely. We further consider this idea below. An additional factor contributing to the reduced abundance of the $b_{8}$ ion is the reduced abundance of the $b_{9}{ }^{2+}$ ion. $\mathrm{MS}^{3}$ data indicate that the $b_{8}$ ion is the dominant product ion formed upon dissociation of the $b_{9}{ }^{2+}$ ion (data not shown). Thus, very likely some fraction of the $b_{8}$ ions is produced normally by a secondary dissociation of the $b_{9}{ }^{2+}$ ion and, as the $b_{9}{ }^{2+}$ pathway becomes less prevalent, so does the abundance of the $b_{8}$ ion (Figure $1 b$ ).

Another example of the effect of oxidized histidine on peptide dissociation patterns is found in the product ion spectrum of His6-oxidized angiotensin I (Figure 1c). The $\mathrm{b}_{6}$ and $\mathrm{y}_{4}$ product ions are no longer the dominant products in the tandem mass spectrum of this ion. 

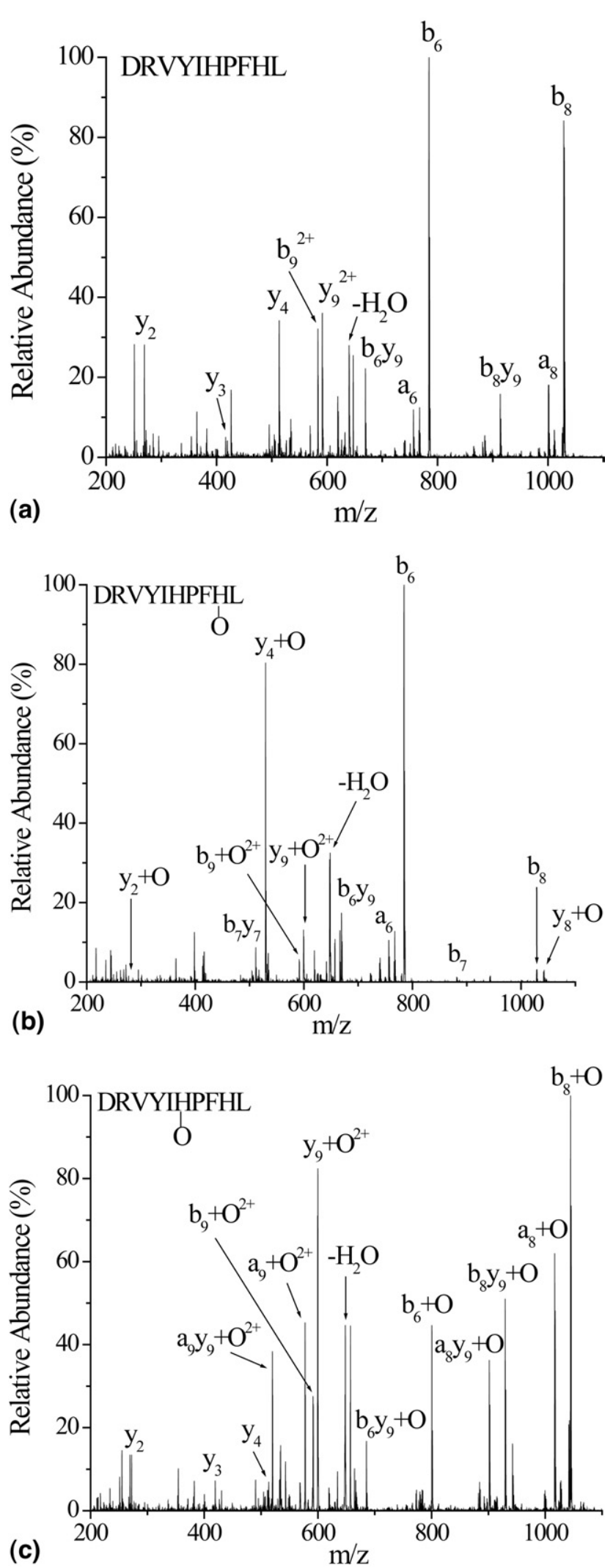

Figure 1. (a) Product ion spectrum of the unoxidized angiotensin I $(\mathrm{M}+2 \mathrm{H})^{2+}$. (b) Product ion spectrum of the His9-oxidized angiotensin $\mathrm{I}(\mathrm{M}+\mathrm{O}+2 \mathrm{H})^{2+}$. (c) Product ion spectrum of the His6-oxidized angiotensin $\mathrm{I}(\mathrm{M}+\mathrm{O}+2 \mathrm{H})^{2+}$. The individual oxidized His6 and oxidized His9 isomers were obtained by separating them by HPLC.
Instead, the $b_{8}, a_{8}, b_{8} y_{9}$, and $y_{9}{ }^{2+}$ ions are the most abundant product ions. Decreased $b_{6}$ and $y_{4}$ ion abundances are likely caused by oxidation at His6, which presumably hinders the dissociation pathway shown in Scheme 1. Because His6 is oxidized but His9 is not, one might expect the $b_{9}{ }^{2+}$ ion to be the most abundant product ion in Figure 1c because it can be formed preferentially by the reaction in Scheme 1. Clearly, the relative ion abundance of $b_{9}{ }^{2+}$ is greater in Figure $1 c$ than that in Figure 1b, although its abundance is not as high as might be expected for a preferential dissociation pathway. Two other pieces of evidence, though, indicate that it is a preferred dissociation pathway. First, at the onset of peptide dissociation, the $b_{9}{ }^{2+}$ is the first product ion observed and, second, $\mathrm{MS}^{3}$ experiments indicate that this ion readily dissociates to some of the other prominent product ions in this spectrum (Figure 1c), including the $b_{8}, a_{8}$, and $a_{9}{ }^{2+}$ product ions (data not shown). Indeed, perhaps the vast difference in ion abundances between the complementary $b_{8}$ and $y_{2}$ product ions in Figure 1c may be an indicator that the $\mathrm{b}_{9}{ }^{2+}$ ion readily undergoes a secondary dissociation to form the $b_{8}$ ion. If the $b_{8}$ product ion were formed predominantly by direct dissociation from the parent ion, then one might expect the ion abundances of the $b_{8}$ and $\mathrm{y}_{2}$ products to be comparable. Because the ion abundances are not comparable, the $b_{8}$ product ion probably arises mainly by dissociation from the $b_{9}{ }^{2+}$ ion. In this case, the complementary ion should be a histidine-containing ion at $m / z 138$, which is below the low $m / z$ cutoff used for these MS/MS experiments.

The effect of histidine oxidation on the dissociation patterns of peptides appears to be a fairly general one when the number of basic residues (such as Arg, Lys, His) is equal to or greater than the number of protons. We have found that the enhanced dissociation adjacent to histidine is muted to varying degrees in several other peptides in which histidine residues are oxidized. These peptides include VSGFHPSDIEVDLL, HYGKHHQTY, DRVYIHPF, VNHVTLSQPK, and NVMGHNW.

This reduced preference to dissociate at peptide bonds adjacent to oxidized histidine residues is partly caused by an oxidation-induced decrease in the proton affinity of oxidized histidine. Several previous studies indicate that by far the most common $+16 \mathrm{Da}$ product formed when histidine is oxidized is 2-oxo-histidine (Scheme 2) [13, 34, 41-45]. Although our MS/MS data are unable to confirm the exact nature of the modification, our results are consistent with the modification shown in Scheme 2 . The proton affinity of 2-oxoimidazole, which is the side-chain analog of 2-oxohistidine, likely has a lower proton affinity than that of imidazole, which has a proton affinity of $942.8 \mathrm{~kJ} / \mathrm{mol}$ [46]. To our knowledge no measurements of the proton affinity of 2-oxo-imidazole have ever been made, but its value is probably similar to the proton affinity of $N, N^{\prime}$-dimethylurea, which is structurally very similar (Scheme 2) and has a proton affinity of $903.3 \mathrm{~kJ} / \mathrm{mol}$ [46]. Furthermore, 2-oxo-histidine is less basic than 
<smiles>CNC(Cc1c[nH]c(=O)[nH]1)C(C)=O</smiles><smiles>CNC(=O)NC</smiles>

\section{2-oxo-histidine}

\section{$\mathbf{N}, N^{\prime}$-dimethylurea}

Scheme 2. Structures of 2-oxo-histidine and $N, N^{\prime}$-dimethylurea

histidine in solution [41]. Thus, histidine oxidation makes protonation of its side chain less favorable and subsequent proton transfer to the adjacent amide bond, as shown in Scheme 1, much less prominent, especially in peptides that have other reasonably basic sites (such as other unoxidized histidines as in angiotensin I). This lower proton affinity explains, in part, the reduced prominence of the C-terminal cleavages adjacent to oxidized His6 and His9 (Figure 1), but it also likely explains the reduced abundances of the $b_{8}$ and $y_{2}$ ions in the product ion spectrum of His9-oxidized angioten$\sin$ I. These relatively prominent ions in the product ion spectrum of unoxidized angiotensin (Figure 1a) may arise from the ability of a proton to be mobilized readily from the side chain of His9 to the amide bond on the $\mathrm{N}$-terminal side of this residue. Upon oxidation, His9's proton affinity is lowered, and the $b_{8} / y_{2}$ formation consequently becomes less prominent.

As indicated above, the reduced proton affinity of oxidized histidine only partly explains elimination of the preferential cleavage on the C-terminal side of histidine residues. In some peptides oxidized histidine will remain one of the more basic sites and therefore a likely site of protonation. In these cases, the side-chain oxidation reduces the preferential cleavage by hindering the second mechanistic step of the dissociation pathway shown in Scheme $\mathbf{1}$ (that is, nucleophilic attack on the adjacent carbonyl). Undoubtedly, the nucleophilicities of the side-chain nitrogens of oxidized histidine are lower than the nucleophilicity of the imino nitrogen in unmodified histidine. Thus, even though oxidized histidine could still be a preferred site of protonation, formation of the bicyclic structure shown in Scheme $\mathbf{1}$ is much less likely. If this is true, then $\mathrm{b}$ ions formed from a cleavage on the C-terminal side of oxidized histidine will have a different structure than $\mathrm{b}$ ions formed from cleavage on the C-terminal side of unmodified histidine. Instead of the bicyclic structure, the $\mathrm{b}$ ions with oxidized histidine would presumably have the usual oxazolone structure. One might then expect the dissociation patterns of these two different $\mathrm{b}$ ions to be dissimilar. Evidence for this contention can be found in $\mathrm{MS}^{3}$ spectra of angiotensin I. Clearly, the $\mathrm{MS}^{3}$ spectrum of the unoxidized $b_{6}$ ion (Figure $2 a$ ) is different from the MS $^{3}$ spectrum of the $b_{6}$ ion that has His 6 oxidized (Figure 2b). Two of the more notable differences are the reduced ion abundances of the $a_{6}$ and $b_{5}$ ions in the spectrum of the oxidized $b_{6}$ ion. As might be expected, differences are observed for dissociation pathways that involve bond-making and bond-breaking steps at positions close to the site of the structural difference (that is, $a_{6}$ and $b_{5}$ product ions). The MS ${ }^{3}$ spectra of the His9oxidized and unoxidized $b_{9}{ }^{2+}$ ions are also very different (data not shown), which further supports the notion that oxidized histidine does not form the bicyclic $b$ ion as does unmodified histidine.

\section{Mistaken Assignment of Oxidation Sites}

The effect of histidine oxidation on peptide dissociation patterns can have an additional practical implication as
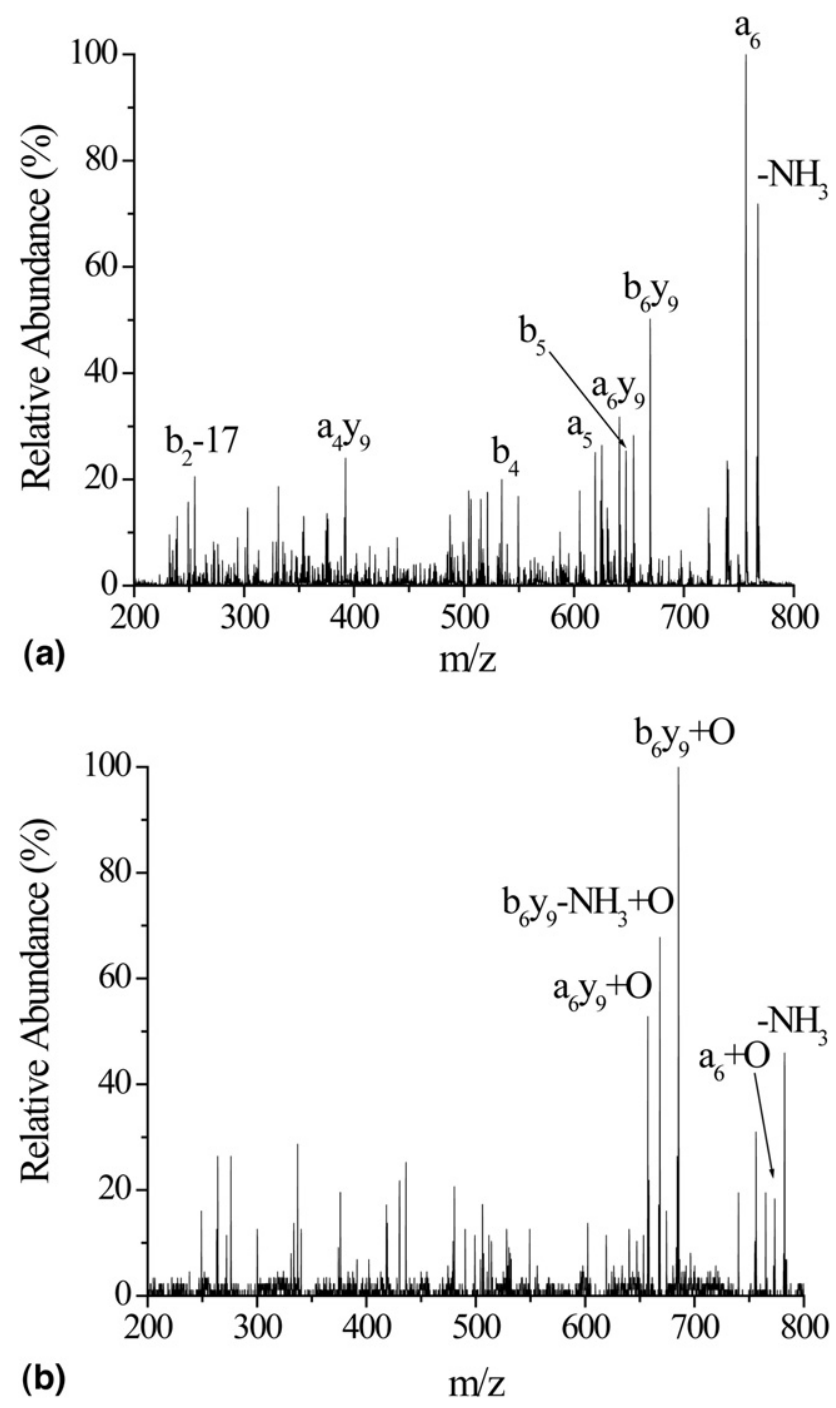

Figure 2. (a) $\mathrm{MS}^{3}$ spectrum of the unoxidized $\mathrm{b}_{6}$ product ion $\left(\mathrm{b}_{6}\right)^{+}$of angiotensin I. (b) MS ${ }^{3}$ spectrum of the oxidized $\mathrm{b}_{6}$ product ion $\left(\mathrm{b}_{6}+\mathrm{O}\right)^{+}$of angiotensin I. 


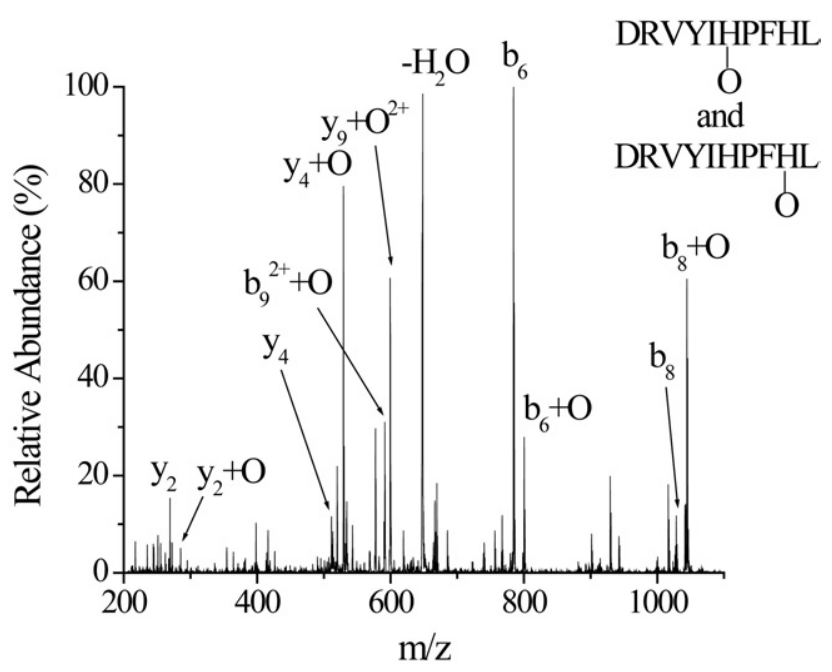

Figure 3. Product ion spectrum of the singly oxidized angioten$\sin \mathrm{I}(\mathrm{M}+\mathrm{O}+2 \mathrm{H})^{2+}$ after simultaneously subjecting the isomeric His6- and His9-oxidized forms to CID without prior separation.

well. When the dissociated peptide consists of two or more isomers that have different sites of oxidation, misinterpretation of the MS/MS spectra can occur such that oxidized residues are inaccurately assigned. Two examples of this phenomenon are given below.

If the singly oxidized form of angiotensin I is subjected to MS/MS analysis without prior chromatographic separation, the resulting product ion spectrum can be difficult to interpret correctly (Figure 3 ). Because oxidized and unoxidized forms of the $\mathrm{y}_{2}, \mathrm{y}_{3}, \mathrm{y}_{4}, \mathrm{~b}_{6}, \mathrm{~b}_{7}$, and $b_{8}$ product ions are observed, one can conclude that oxidized angiotensin is a mixture of more than one isomer differing in the site of oxidation. By comparing the percentages of oxidized forms for each product ion, observing the absence of unoxidized $y_{5}$ and $b_{9}$ ions (Table 1), and noting the absence of an oxidized $b_{5}$ ion, one can further conclude that His6, Pro7, His9, and possibly Phe 8 are oxidized. For example, the $y_{2}$ and $y_{3}$ product ions are both about 25 and $15 \%$ oxidized, respectively, whereas the $\mathrm{y}_{4}$ product ion is $90 \%$ oxidized. These data suggest that Pro7 is oxidized along with His9. Similarly, the percentages of oxidized product ions in the $b$ series from $b_{6}$ to $b_{9}$ suggest that His6, Pro7, His9, and possibly Phe8 are oxidized. Clearly, these $\mathrm{y}$ - and $\mathrm{b}$-series are inconsistent with respect to whether Phe8 is oxidized. A series of $\mathrm{MS}^{\mathrm{n}}$ experiments, including $\mathrm{MS}^{\mathrm{n}}$ of the $\mathrm{y}_{4}+\mathrm{O},\left(\mathrm{b}_{9}+\mathrm{O}\right)^{2+}$, and the $\mathrm{b}_{8}+$ $\mathrm{O}$ product ions, are required to clarify that Phe 8 is not oxidized (data not shown). Furthermore, $\mathrm{MS}^{\mathrm{n}}$ data indicate that Pro7 is also not oxidized and confirm that oxidation is limited to only His6 and His9. Thus, the singly oxidized form of angiotensin is really only a mixture of two isomers. The misleading interpretation of the MS/MS spectrum in Figure 3 arises because oxidative modifications at His6 and His9 suppress the normally prominent dissociation pathways adjacent to these residues. In the His6-oxidized angiotensin ions, formation of the $\mathrm{b}_{6}+\mathrm{O}$ and $\mathrm{y}_{4}$ ions is suppressed, whereas formation of the $\mathrm{b}_{8}+\mathrm{O}$ and $\mathrm{y}_{2}$ product ions is relatively unaffected. In contrast, formation of the $b_{8}$ and $\mathrm{y}_{2}+\mathrm{O}$ ions is suppressed in the His9-oxidized ions, whereas formation of the $b_{6}$ and $y_{4}+O$ product ions is unaffected. These combined effects make it easy to misinterpret the data in Figure 3.

The product ion spectrum of the singly oxidized prion peptide (Ac-PHGGGWGQ-NH ${ }_{2}$ ) is also difficult to interpret correctly (Figure 4a). A prominent b-series is observed and, upon examining the b-series, the parent ion at $m / z 852.4[\mathrm{M}+\mathrm{O}+\mathrm{H}]^{+}$appears to be a mixture of perhaps five isomeric peptides differing by the site of oxidation. This conclusion arises from the series of $b$ ions from $b_{2}$ to $b_{5}$ that have increasing percentages of oxidized forms (Table 2). The partial oxidation $(15 \%)$ of the $b_{2}$ product ion indicates that either proline or histidine is oxidized in some of the peptides; $\mathrm{MS}^{3}$ data confirm that histidine but not proline is oxidized. Complete oxidation $(100 \%)$ of the $b_{6}$ ion indicates that Gly3, Gly4, Gly5, and/or Trp6 are oxidized. Because the relative oxidation percentages increase along the series $b_{3}$ to $b_{6}$, the data suggest that Gly3, Gly4, Gly5, and Trp6 are all oxidized. This conclusion, however, is incorrect. Not only does the lack of a side chain make it unlikely that any of the glycine residues are oxidized [30], but $\mathrm{MS}^{3}$ spectra of the $\mathrm{b}_{5}+$ $\mathrm{O}, \mathrm{b}_{4}+\mathrm{O}$, and $\mathrm{b}_{3}+\mathrm{O}$ product ions indicate that His2

Table 1. Percentage of oxidized product ions observed in the tandem mass spectrum of the doubly charged ion of singly oxidized angiotensin $(\mathrm{M}+\mathrm{O}+2 \mathrm{H})^{2+}$

\begin{tabular}{cccc}
\hline $\begin{array}{c}\text { Product } \\
\text { ion }\end{array}$ & $m / z_{\text {unoxidized }}{ }^{\mathrm{a}}$ & $m / z_{\text {oxidized }}{ }^{\mathrm{a}}$ & $\begin{array}{c}\text { Percentage } \\
\text { oxidized }^{\mathrm{b}}\end{array}$ \\
\hline \hline $\mathrm{y}_{2}$ & 269 & 285 & 25 \\
$\mathrm{y}_{3}$ & 416 & 432 & 15 \\
$\mathrm{y}_{4}$ & 513 & 529 & 90 \\
$\mathrm{y}_{5}$ & 649 & 665 & $\sim 100^{\mathrm{c}}$ \\
$\mathrm{y}_{6}$ & 763 & 779 & 100 \\
$\mathrm{y}_{7}$ & 926 & 942 & 100 \\
$\mathrm{y}_{8}$ & 1025 & 1041 & 100 \\
$\mathrm{y}_{9}{ }^{2+}$ & 591 & 599 & $-{ }^{\mathrm{d}}$ \\
$\mathrm{b}_{2}$ & 272 & 288 & 0 \\
$\mathrm{~b}_{3}$ & 371 & 387 & 0 \\
$\mathrm{~b}_{4}$ & 534 & 550 & 0 \\
$\mathrm{~b}_{5}$ & 647 & 663 & 0 \\
$\mathrm{~b}_{6}$ & 784 & 800 & 20 \\
$\mathrm{~b}_{7}$ & 881 & 897 & $\sim 45^{\mathrm{e}}$ \\
$\mathrm{b}_{8}$ & 1028 & 1044 & 80 \\
$\mathrm{~b}_{9}{ }^{2+}$ & 583 & 591 & 100 \\
\hline
\end{tabular}

${ }^{\text {aT These }} \mathrm{m} / \mathrm{z}$ ratios correspond to the nominal $\mathrm{m} / \mathrm{z}$ ratio of the observed product ions.

${ }^{b}$ The percentage oxidized is obtained by dividing the ion abundance of the oxidized product ion by the sum of the ion abundances of the oxidized and unoxidized product ions. The values typically had a relative standard deviation of about $20 \%$.

${ }^{\mathrm{c}}$ The ion abundance of the unoxidized $\mathrm{y}_{5}$ product ion is difficult to accurately determine because of an interfering ion $\mathrm{m} / \mathrm{z} 648.5$, which corresponds to a loss of $\mathrm{NH}_{3}$ from the parent ion. A high resolution scan, however, suggests that no unoxidized $y_{5}$ ion at $m / z 649$ is present. ${ }^{\mathrm{d}}$ The ion abundance of the unoxidized $\mathrm{y}_{9}{ }^{2+}$ product ion cannot be determined because it is isobaric with the oxidized $b_{9}{ }^{2+}$ product ion. eThe ion abundance of the $b_{7}$ product ion is very low, which makes determination of the percentage oxidized difficult. 

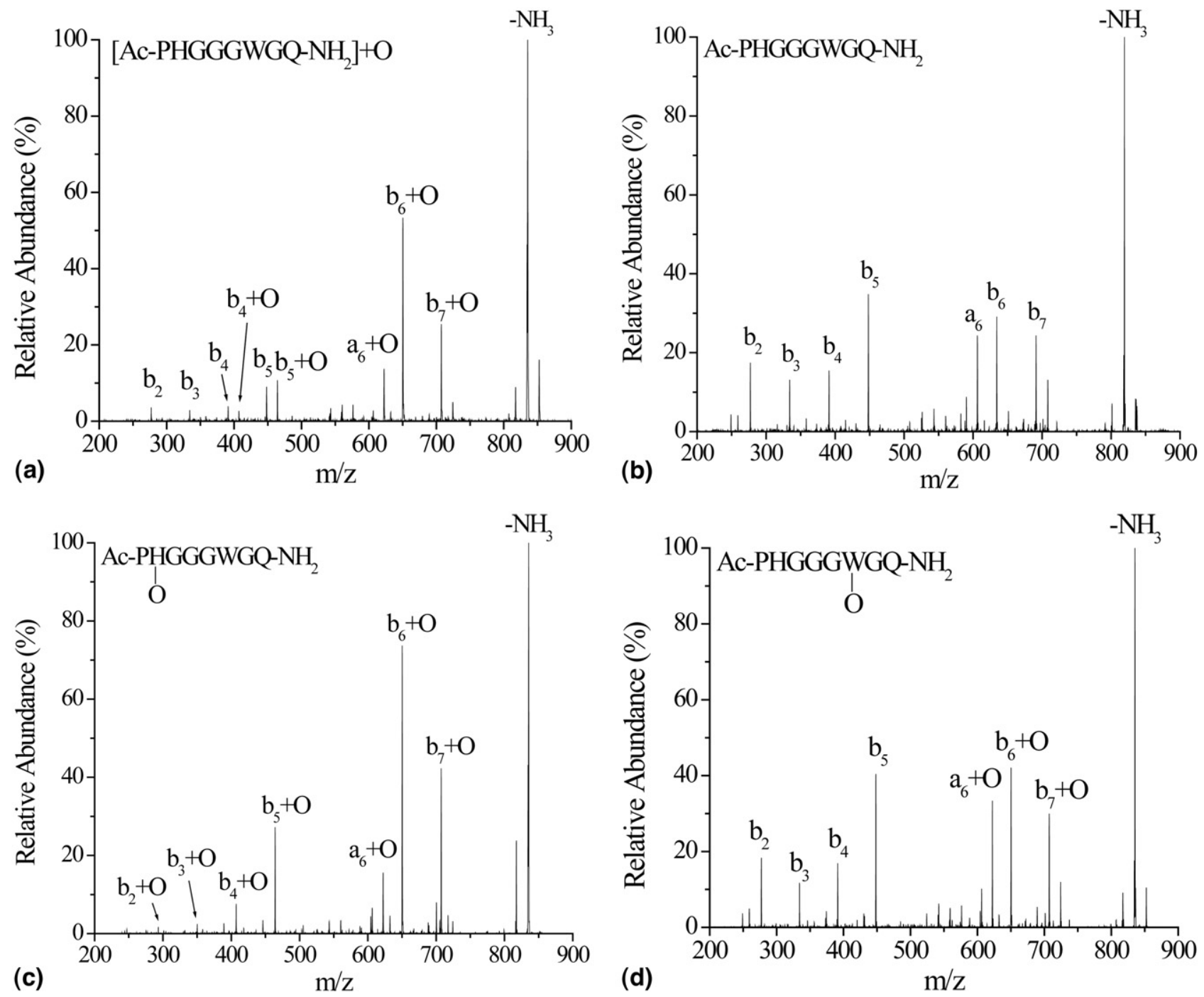

Figure 4. (a) Product ion spectrum of the singly oxidized prion peptide $(\mathrm{M}+\mathrm{O}+\mathrm{H})^{+}$after simultaneously subjecting the isomeric oxidized forms to CID without prior separation. (b) Product ion spectrum of the unoxidized prion peptide $(\mathrm{M}+\mathrm{H})^{+}$. (c) Product ion spectrum of the His2-oxidized prion peptide $(\mathrm{M}+\mathrm{O}+\mathrm{H})^{+}$. (d) Product ion spectrum of the Trp6-oxidized prion peptide $(\mathrm{M}+\mathrm{O}+\mathrm{H})^{+}$. The individual oxidized His2 and oxidized Trp6 isomers were obtained by separating them by HPLC.

but not Gly3, Gly4, or Gly5 is oxidized. Figure 5 is a representative $\mathrm{MS}^{3}$ spectrum of the $\mathrm{b}_{4}+\mathrm{O}$ product ion. The absence of any unoxidized $b_{2}$ or $b_{3}$ product ions and the absence of an oxidized $b_{1}$ ion demonstrate that oxidation is limited to His2. Interestingly, $\mathrm{b}_{1}$ ions are often not observed in the product ion spectra of peptide ions, but perhaps the acetylated $\mathrm{N}$-terminus allows this ion to form. An MS ${ }^{3}$ spectrum of the $\mathrm{b}_{6}+\mathrm{O}$ product ion indicates that Trp6 is also oxidized (data not shown). So, the singly oxidized ion at $\mathrm{m} / \mathrm{z} 852$ is only a mixture of two isomers, one in which His2 is oxidized and another in which Trp6 is oxidized.

The potentially incorrect interpretation of the product ion spectrum in Figure 4a arises because oxidized histidine hinders the dissociation pathways giving rise to the $\mathrm{b}_{2}+\mathrm{O}, \mathrm{b}_{3}+\mathrm{O}$, and $\mathrm{b}_{4}+\mathrm{O}$ product ions. This
Table 2. Percentage of oxidized product ions observed in the tandem mass spectrum of the singly charged ion of singly oxidized prion peptide $(\mathrm{M}+\mathrm{O}+\mathrm{H})^{+}$

\begin{tabular}{cccc}
\hline $\begin{array}{c}\text { Product } \\
\text { ion }\end{array}$ & $m / z_{\text {unoxidized }}{ }^{\mathrm{a}}$ & $m / z_{\text {oxidized }}{ }^{\mathrm{a}}$ & $\begin{array}{c}\text { Percentage } \\
\text { oxidized }^{\mathrm{b}}\end{array}$ \\
\hline \hline $\mathrm{b}_{2}$ & 277 & 293 & 15 \\
$\mathrm{~b}_{3}$ & 334 & 350 & 25 \\
$\mathrm{~b}_{4}$ & 391 & 407 & 40 \\
$\mathrm{~b}_{5}$ & 448 & 464 & 55 \\
$\mathrm{a}_{6}$ & 606 & 622 & 100 \\
$\mathrm{~b}_{6}$ & 634 & 650 & 100 \\
$\mathrm{~b}_{7}$ & 691 & 707 & 100 \\
\hline
\end{tabular}

${ }^{\text {aT These }} \mathrm{m} / \mathrm{z}$ ratios correspond to the nominal $\mathrm{m} / \mathrm{z}$ ratio of the observed product ions.

${ }^{\mathrm{b}}$ The percentage oxidized is obtained by dividing the ion abundance of the oxidized product ion by the sum of the ion abundances of the oxidized and unoxidized product ions. The values typically had a relative standard deviation of about $20 \%$. 


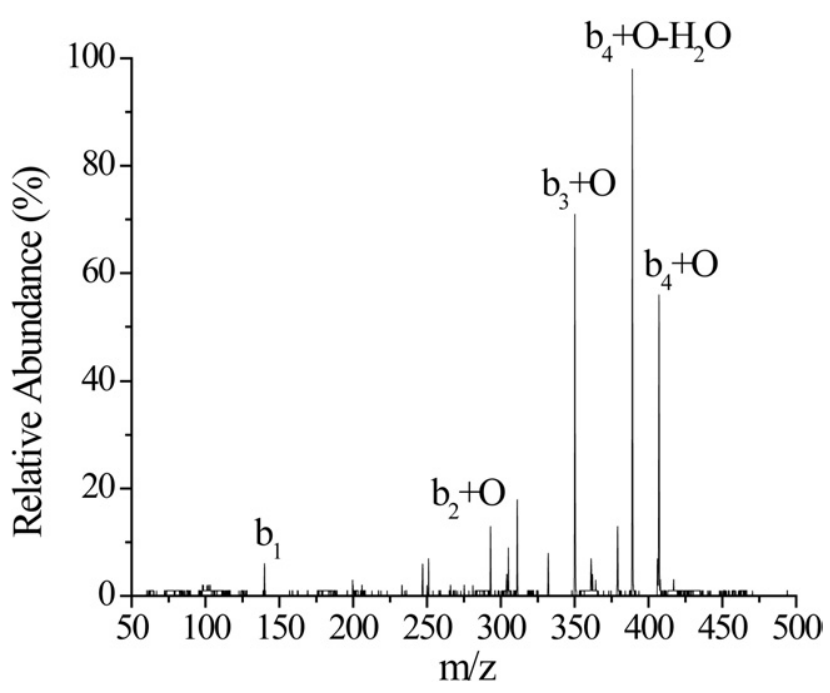

Figure 5. $\mathrm{MS}^{3}$ spectrum of the oxidized $\mathrm{b}_{4}$ product ion $\left(\mathrm{b}_{4}+\mathrm{O}\right)^{+}$ of the prion peptide.

becomes clear when the His2- and Trp6-oxidized forms of the prion peptide are separated and their product ion spectra are acquired separately (Figure $4 b, c$, and d). Upon comparing the product ion spectrum of the unmodified (Figure 4b), His2-oxidized (Figure 4c), and Trp6-oxidized (Figure 4d) forms of the prion peptide, clearly histidine oxidation essentially eliminates the $b_{2}$ $+\mathrm{O}$ ion channel. Oxidation to His2 also reduces the abundances of $b_{3}+O$ and $b_{4}+O$ product ions to differing degrees. The net effect is that when both oxidized isomers are simultaneously subjected to MS/ MS, as in Figure 4a, incorrect assignment of the oxidized residues is a real possibility.

\section{Avoiding Spectral Misinterpretation}

Mistakenly assigning oxidized residues is obviously a problem, but there are several potential ways to avoid this situation. Two means are evident from the data above. Additional stages of MS/MS (or MS ${ }^{\mathrm{n}}$ ) are capable of correctly identifying the oxidized residues in angiotensin I and the prion peptide. Not all mass spectrometers, however, are as readily able to perform such $\mathrm{MS}^{\mathrm{n}}$ experiments as a quadrupole ion trap mass spectrometer, which was used in these studies. LC separation of any oxidized peptide isomers before mass spectral analysis is another approach to avoid complications associated with simultaneously subjecting two or more isomers to MS/MS analysis. Indeed, the MS/MS spectra of the His6- and His9-oxidized forms of angiotensin (Figure 1) were obtained after LC separation. Unfortunately, separating these isomers required significant optimization and LC conditions that are atypical for normal peptide or protein digest separations. The ability to separate isomers using LC cannot be guaranteed for every oxidized peptide, so this approach to avoiding spectral misinterpretation may not be generally effective.
Another way to avoid the effects of histidine oxidation would be to use a dissociation approach that is less affected by amino acid side-chain chemistry. One such approach is $\mathrm{N}$-terminal derivatization with sulfonic acid. Keough and coworkers previously showed that a simple one-step derivatization with sulfobenzoic acid cyclic anhydride is a useful approach for de novo sequencing of a wide range of peptides [47, 48]. When derivatized with this strong acid, peptide ions have an additional proton that is readily mobilized along the backbone to facilitate cleavage at almost all peptide bonds. We have found that derivatization with this group can overcome the interpretation difficulties associated with dissociating peptide ions with more than one oxidized isomer. As an example of this approach, Figure 6 shows the product ion spectrum of the doubly charged derivatized form of oxidized angiotensin I. From Figure 6 and the percentages of oxidized product ions (Table 3), localizing the oxidation to His6 and His9 is more straightforward. The oxidation percentages for the $y_{2}$ and $y_{4}$ product ions are very close and the oxidation percentages of the $b_{6}{ }^{*}$ and $b_{8}{ }^{*}$ ions are also very close. The slight differences in oxidation percentages for these product ion pairs could have arisen from experimental error, a slight effect of oxidation on the dissociation patterns, or a small percentage of oxidation actually occurring at Pro7 and/or Phe8. The latter possibility is ruled out by $\mathrm{MS}^{3}$ data on several of the product ions in Figure 6, which provide no evidence for oxidation at Pro7 or Phe8. Also, LC-MS of angiotensin I after oxidation (inset, Figure 6) provides evidence for only two singly oxidized forms (that is, $[\mathrm{M}+\mathrm{O}]$ ) of the peptide.

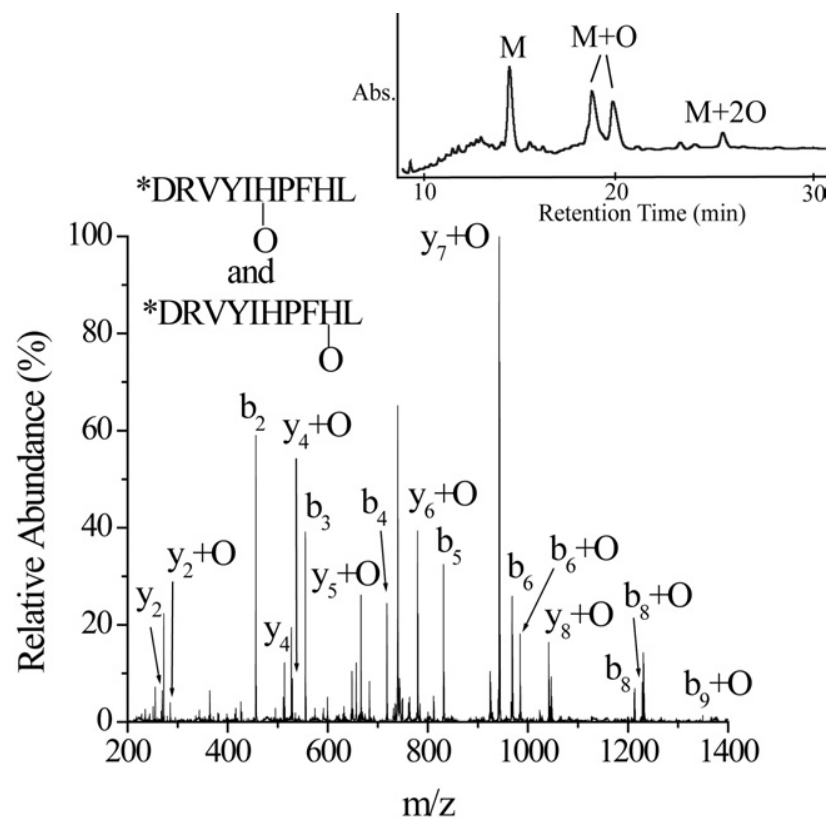

Figure 6. Product ion spectrum of the derivatized form of oxidized angiotensin $\mathrm{I}\left(\mathrm{M}+\mathrm{O}+\mathrm{C}_{7} \mathrm{H}_{4} \mathrm{SO}_{4}+2 \mathrm{H}\right)^{+}$. All the $\mathrm{b}$ ions contain the sulfonic acid group. 
Table 3. Percentage of oxidized product ions observed in the tandem mass spectrum of the doubly charged derivatized ion of singly oxidized angiotensin $\left(\mathrm{M}+\mathrm{O}+\mathrm{C}_{7} \mathrm{H}_{4} \mathrm{SO}_{4}+2 \mathrm{H}\right)^{+}$

\begin{tabular}{cccc}
\hline $\begin{array}{c}\text { Product } \\
\text { ion }\end{array}$ & $m / z_{\text {unoxidized }}{ }^{\mathrm{a}}$ & $m / z_{\text {oxidized }}{ }^{\mathrm{a}}$ & $\begin{array}{c}\text { Percentage } \\
\text { oxidized }^{\mathrm{b}}\end{array}$ \\
\hline \hline $\mathrm{y}_{2}$ & 269 & 285 & 40 \\
$\mathrm{y}_{3}$ & 416 & 432 & $-^{\mathrm{c}}$ \\
$\mathrm{y}_{4}$ & 513 & 529 & 45 \\
$\mathrm{y}_{5}$ & 649 & 665 & 100 \\
$\mathrm{y}_{6}$ & 763 & 779 & 100 \\
$\mathrm{y}_{7}$ & 926 & 942 & 100 \\
$\mathrm{y}_{8}$ & 1025 & 1041 & 100 \\
$\mathrm{y}_{9}{ }^{2+}$ & 591 & 599 & 100 \\
$\mathrm{~b}_{2}$ & 456 & 472 & 0 \\
$\mathrm{~b}_{3}$ & 555 & 571 & 0 \\
$\mathrm{~b}_{4}$ & 718 & 734 & 0 \\
$\mathrm{~b}_{5}$ & 831 & 847 & 0 \\
$\mathrm{~b}_{6}$ & 968 & 984 & 45 \\
$\mathrm{~b}_{7}$ & 1065 & 1081 & $-{ }^{\mathrm{c}}$ \\
$\mathrm{b}_{8}$ & 1212 & 1228 & 55 \\
$\mathrm{~b}_{9}$ & 1333 & 1349 & 100 \\
\hline
\end{tabular}

aThese $\mathrm{m} / \mathrm{z}$ ratios correspond to the nominal $\mathrm{m} / \mathrm{z}$ ratio of the observed product ions.

${ }^{\mathrm{b}}$ The percentage oxidized is obtained by dividing the ion abundance of the oxidized product ion by the sum of the ion abundances of the oxidized and unoxidized product ions. The values typically had a relative standard deviation of about $20 \%$.

${ }^{c}$ The $y_{3}$ and $b_{7}$ product ions were not observed.

\section{Conclusions}

Oxidation of histidine can lead to very noticeable changes in the dissociation patterns of peptide ions containing this residue. The preferential cleavage at the C-terminal side of histidine, which is often observed in product ion spectra of peptides with basic residues that equal or exceed the number of protons on the peptide, is reduced or eliminated upon oxidation of histidine. This effect is caused by the lower proton affinity and weaker nucleophilicity of 2-oxo-histidine compared to that of histidine.

Practically speaking, histidine oxidation can lead to spectral misinterpretations. This is especially a problem when an oxidized peptide consists of more than one isomer differing by the site of oxidation. The use of $\mathrm{MS}^{\mathrm{n}}$ and LC-MS/MS can often avoid misassignments of oxidized residues, but the inability to do $\mathrm{MS}^{\mathrm{n}}$ on all mass spectrometers and the special chromatographic conditions required to separate oxidized isomers limit the general utility of these approaches. An alternate solution is to derivatize the $\mathrm{N}$-terminus of the peptide with sulfobenzoic acid. This derivatization step represents an easy and general approach to avoid spectral misinterpretations because this modification reduces the effect of side-chain chemistry on peptide ion dissociation pathways. We suspect other techniques that are relatively insensitive to side-chain chemistry, such as electron-capture dissociation and electron-transfer dissociation, will also be effective at generating product ion spectra that can be interpreted in a more straightforward manner.

\section{Acknowledgments}

This work was supported by National Institute of General Medical Sciences Grant RO1 GM-075092.

\section{References}

1. Maleknia, S. D.; Brenowitz, M.; Chance, M. R. Millisecond Radiolytic Modification of Peptides by Synchrotron X-rays Identified by Mass Spectrometry. Anal. Chem. 1999, 71, 3965-3973.

2. Maleknia, S. D.; Chance, M. R.; Downard, K. M. Electrospray-assisted Modification of Proteins: A Radical Probe of Protein Structure. Rapid Commun. Mass Spectrom. 1999, 13, 2352-2358.

3. Kiselar, J. G.; Maleknia, S. D.; Sullivan, M.; Downard, K. M.; Chance, M. R. Hydroxyl Radical Probe of Protein Surfaces Using Synchrotron X-ray Radiolysis and Mass Spectrometry. Int. J. Radiat. Biol. 2002, 78, 101-114.

4. Guan, J.; Vorobiev, S.; Almo, S. C.; Chance, M. R. Mapping the G-Actin Binding Surface of Cofilin Using Synchrotron Protein Footprinting. Biochemistry 2002, 41, 5765-5775.

5. Kiselar, J. G.; Janmey, P. A.; Almo, S. C.; Chance, M. R. Visualizing the $\mathrm{Ca}^{2+}$-Dependent Activation of Gelsolin by Using Synchrotron Footprinting. Proc. Natl. Acad. Sci. U.S.A. 2003, 100, 3942-3947.

6. Wong, J. W.; Maleknia, S. D.; Downard, K. M. Study of the Ribonuclease-S-Protein-Peptide Complex Using a Radical Probe and Electrospray Ionization Mass Spectrometry. Anal. Chem. 2003, 75, 1557-1563.

7. Sharp, J. S.; Becker, J. M.; Hettich, R. L. Protein Surface Mapping by Chemical Oxidation: Structural Analysis by Mass Spectrometry. Anal. Biochem. 2003, 313, 216-225.

8. Sharp, J. S.; Becker, J. M.; Hettich, R. L. Analysis of Protein Solvent Accessible Surfaces by Photochemical Oxidation and Mass Spectrometry. Anal. Chem. 2004, 76, 672-683.

9. Guan, J. Q.; Chance, M. R. Structural Proteomics of Macromolecular Assemblies Using Oxidative Footprinting and Mass Spectrometry. Trends Biochem. Sci. 2005, 30, 583-592.

10. Hambly, D. M.; Gross, M. L. Laser Flash Photolysis of Hydrogen Peroxide to Oxidize Protein Solvent-Accessible Residues on the Microsecond Timescale. J. Am. Soc. Mass Spectrom. 2005, 16, 2057-2063.

11. Kurahashi, T.; Miyazaki, A.; Suwan, S.; Isobe, M. Extensive Investigations on Oxidized Amino Acid Residues in $\mathrm{H}_{2} \mathrm{O}_{2}$-Treated $\mathrm{Cu}, \mathrm{Zn}$-SOD Protein with LC-ESI-Q-TOF-MS, MS/MS for the Determination of the Copper-Binding Site. J. Am. Chem. Soc. 2001, 123, 9268-9278.

12. Hovorka, S. W.; Williams, T. D.; Schöneich, C. Characterization of the Metal-Binding Site of Bovine Growth Hormone through Site-Specific metal Catalyzed Oxidation and High-Performance Liquid Chromatography-Tandem Mass Spectrometry. Anal. Biochem. 2002, 300, 206-211.

13. Schöneich, C.; Williams, T. D. Cu(II)-Catalyzed Oxidation of $\beta$-Amyloid Peptide Targets His13 and His14 over His6: Detection of 2-Oxohistidine by HPLC-MS/MS. Chem. Res. Toxicol. 2002, 15, 717-722.

14. Lim, J.; Vachet, R. W. Development of a Methodology Based on Metal-Catalyzed Oxidation Reactions and Mass Spectrometry to Determine the Metal Binding Sites in Copper Metalloproteins. Anal. Chem. 2003, 75, 1164-1172.

15. Lim, J.; Vachet, R. W. Using Mass Spectrometry to Study CopperProtein Binding Under Native and Non-Native Conditions: $\beta$-2-Microglobulin. Anal. Chem. 2004, 76, 3498-3504.

16. Bridgewater, J. D.; Vachet, R. W. Metal-Catalyzed Oxidation Reactions and Mass Spectrometry: The Roles of Ascorbate and Different Oxidizing Agents in Determining Cu-Protein-Binding Sites. Anal. Biochem. 2005, $41,122-130$

17. Bridgewater, J. D.; Vachet, R. W. Using Microwave-Assisted MetalCatalyzed Oxidation Reactions and Mass Spectrometry to Increase the Rate at Which the Copper-Binding Sites of a Protein Are Determined. Anal. Chem. 2005, 77, 4649-4653.

18. Bridgewater, J. D.; Lim, J.; Vachet, R. W. Transition Metal-Peptide Binding Studied by Metal-Catalyzed Oxidation Reactions and Mass Spectrometry. Anal. Chem. 2006, 78, 2432-2438.

19. Burlet, O.; Yang, C.-Y.; Gaskell, S. J. Influence of Cysteine to Cysteic Acid Oxidation on the Collision-Activated Decomposition of Protonated Peptides: Evidence for Intraionic Interactions. J. Am. Soc. Mass Spectrom. 1992, 3, 337-344.

20. Cox, K. A.; Gaskell, S. J.; Morris, M.; Whiting, A. Role of the Site of Protonation in the Low-Energy Decompositions of Gas-Phase Peptide Ions. J. Am. Soc. Mass Spectrom. 1996, 7, 522-531.

21. Summerfield, S. G.; Cox, K. A.; Gaskell, S. J. The Promotion of $d$-Type Ions during the Low Energy Collision-Induced Dissociation of Some Cysteic Acid-Containing Peptides. J. Am. Soc. Mass Spectrom. 1997, 8 , 25-31.

22. Tsaprailis, G.; Nair, H.; Somogyi, A.; Wysocki, V. H.; Zhong, W.; Futrell J. H.; Summerfield, S. G.; Gaskell, S. J. Influence of Secondary Structure on the Fragmentation of Protonated Peptides. J. Am. Chem. Soc. 1999, 121, 5142-5154

23. Wang, Y.; Vivekananda, S.; Men, L.; Zhang, Q. Fragmentation of Protonated Ions of Peptides Containing Cysteine, Cysteine Sulfinic Acid, and Cysteine Sulfonic Acid. J. Am. Soc. Mass Spectrom. 2004, 15, 697-702. 
24. Men, L.; Wang, Y. Further Studies on the Fragmentation of Protonated Ions of Peptides Containing Aspartic Acid, Glutamic Acid, Cysteine Sulfinic Acid, and Cysteine Sulfonic Acid. Rapid Commun. Mass Spectrom. 2005, 19, 23-30.

25. Jiang, X.; Smith, J. B.; Abraham, E. C. Identification of a MS-MS Fragment Diagnostic for Methionine Sulfoxide. J. Mass Spectrom. 1996, 31, 1309-1310.

26. Lagerwerf, F. M.; van de Weert, M.; Heerma, W.; Haverkamp, J. Identification of Oxidized Methionine in Peptides. Rapid Commun. Mass Spectrom. 1996, 10, 1905-1910.

27. Qin, J.; Chait, B. T. Identification and Characterization of Posttranslational Modifications of Proteins by MALDI Ion Trap Mass Spectrometry. Anal. Chem. 1997, 69, 4002-4009.

28. O'Hair, R. A. J.; Reid, G. E. Neighboring Group versus cis-Elimination Mechanisms for Side Chain Loss from Protonated Methionine, Methionine Sulfoxide and their Peptides. Eur. Mass Spectrom. 1999, 5, 325-334.

29. Reid, G. E.; Roberts, K. D.; Kapp, E. A.; Simpson, R. J. Statistical and Mechanistic Approaches to Understanding the Gas-Phase Fragmentation Behavior of Methionine Sulfoxide Containing Peptides. J. Proteome Res. 2004, 3, 751-759.

30. Buxton, G. V.; Greenstock, C. L.; Helman, W. P.; Ross, A. B. Critical Review of Rate Constants for Reactions of Hydrated Electrons, Hydrogen Atoms, and Hydroxyl Radicals in Aqueous Solution. J. Phys. Chem. Ref. Data 1988, 17, 513-886.

31. Stadtman, E. R.; Berlett, B. S. Reactive Oxygen-Mediated Protein Oxidation in Aging and Disease. Chem. Res. Toxicol. 1997, 10, 485-494.

32. Schöneich, C. Reactive Oxygen Species and Biological Aging: A Mechanistic Approach. Exp. Gerontol. 1999, 34, 19-34.

33. Davies, M. J. The Oxidative Environment and Protein Damage. Biochim. Biophys. Acta 2005, 1703, 93-109.

34. Uchida, K.; Kawakishi, S. 2-Oxo-Histidine as a Novel Biological Marker for Oxidatively Modified Proteins. FEBS Lett. 1993, 332, 208-210.

35. Huang, Y.; Wysocki, V. H.; Tabb, D. L.; Yates, J. R. The Influence of Histidine on Cleavage C-terminal to Acidic Residues in Doubly-Protonated Tryptic Peptides. Int. I. Mass Spectrom. 2002, 219, 233-244.

36. Tabb, D. L.; Smith, L. L.; Breci, L. A.; Wysocki, V. H.; Lin, D.; Yates, J. R. Statistical Characterization of Ion Trap Tandem Mass Spectra from Doubly Charged Tryptic Peptides. Anal. Chem. 2003, 75, 1155-1163.
37. Wysocki, V. H.; Tsaprailis, G.; Smith, L. L.; Breci, L. A. Mobile and Localized Protons: A Framework for Understanding Peptide Dissociation. J. Mass Spectrom. 2000, 35, 1399-1406.

38. Farrugia, J. M.; Taverner, T.; O'Hair, R. A. J. Side-Chain Involvement in the Fragmentation Reactions of the Protonated Methyl Esters of Histidine and Its Peptides. Int. J. Mass Spectrom. 2001, 209, 99-112.

39. Farrugia, J. M.; O'Hair, R. A. J.; Reid, G. E. Do All b Ions have Oxazolone Structures? Multistage Mass Spectrometry and $a b$ initio Studies on Protonated N-acyl Amino Acid Methyl Ester Model Systems. Int. J. Mass Spectrom. 2001, 210/211, 71-87.

40. Tsaprailis, G.; Nair, H.; Zhong, W.; Kuppannan, K.; Futrell, J. H.; Wysocki, V. H. A Mechanistic Investigation of the Enhanced Cleavage at Histidine in the Gas-Phase Dissociation of Protonated Peptides. Anal. Chem. 2004, 76, 2083-2094.

41. Uchida, K.; Kawakishi, S. Ascorbate-Mediated Specific Oxidation of the Imidazole Ring in a Histidine Derivative. Bioorg. Chem. 1989, 17, $330-343$.

42. Lewisch, S. A.; Levine, R. L. Determination of 2-Oxohistidine by Amino Acid Analysis. Anal. Biochem. 1995, 231, 440-446.

43. Zhao, F.; Ghezzo-Schöneich, E.; Aced, G. I.; Hong, J.; Milby, T.; Schöneich, C. Metal-Catalyzed Oxidation of Histidine in Human Growth Hormone: Mechanism, Isotope Effects, and Inhibition by a Mild Denaturing Alcohol. J. Biol. Chem. 1997, 272, 9019-9029.

44. Schöneich, C. Mechanisms of Metal-Catalyzed Oxidation of Histidine to 2-Oxo-Histidine in Peptides and Proteins. J. Pharm. Biomed. Anal. 2000, 21, 1093-1097.

45. Hovorka, S. W.; Biesiada, H.; Williams, T. D.; Hühmer, A.; Schöneich, C. High Sensitivity of $\mathrm{Zn}^{2+}$ Insulin to Metal-Catalyzed Oxidation: Detection of 2-Oxo-Histidine by Tandem Mass Spectrometry. Pharm. Res. 2002, 19, 530-537.

46. Hunter, E. P.; Lias, S. G. Evaluated Gas Phase Basicities and Proton Affinities of Molecules: An Update. J. Phys. Chem. Ref. Data 1998, 27, 413-656.

47. Keough, T.; Youngquist, R. S.; Lacey, M. P. A Method for HighSensitivity Peptide Sequencing Using Postsource Decay Matrix-Assisted Laser Desorption Ionization Mass Spectrometry. Proc. Natl. Acad. Sci. U.S.A. 1999, 96, 7131-7136.

48. Bauer, M. D.; Sun, Y.; Keough, T.; Lacey, M. P. Sequencing of Sulfonic Acid Derivatized Peptides by Electrospray Mass Spectrometry. Rapid Commun. Mass Spectrom. 2000, 14, 924-929. 